\title{
Get ready for ocean acidification
}

\author{
Sam Dupont and Hans Pörtner call for experiments of greater complexity that can \\ probe how plummeting $\mathrm{pH}$ will affect marine ecosystems as the climate warms.
}

$\mathrm{O}$ ceans are becoming more acidic as they draw rising levels of carbon dioxide from the atmosphere. Since 1850 , the acidity of the surface ocean has increased by almost $30 \%$, and could double or triple further by 2100 as the growing human ₹ population leads to higher $\mathrm{CO}_{2}$ emissions. Ocean acidification will cause marine ecosystems to undergo major changes that scientists are only beginning to understand.

Past work has tended to focus on the immediate responses of single marine species to acidification, but researchers now know that some species are more resilient to rising acidity than others. The challenge is to understand how whole ecosystems react to a range of climate-related stressors, including temperature.

We believe that the ocean-acidification field must move away from testing only individual species in simple experimental conditions and instead perform more complex and extended experiments (see page 420). These would involve all life stages of target species and their food webs, would embrace environmental complexity and last for months to years. The aim should be to derive a set of unifying principles to help identify which sensitive species and ecosystems to protect in the face of rising ocean acidity.

\section{SURPRISING RESILIENCE?}

We have known for decades that ocean acidification threatens calcifying organisms such as corals, clams, mussels and brittlestars - some to the point of possible extinction within decades. It came as a surprise in the past few years that some calcifier species are resilient to acidification, such as the mussels that thrive in Kiel fjord in Germany despite a seasonal flow of $\mathrm{CO}_{2}$-rich waters ${ }^{1}$.

Other organisms can be both vulnerable and resilient at different times in their life cycles, such as some phytoplankton, fish and sea urchins. Initially, female green sea urchins (Strongylocentrotus droebachiensis) that are exposed to acidification produce around onefifth the number of eggs produced by urchins in current ocean $\mathrm{pH}$ conditions. But after 16 months, adults acclimatize and reproduce as normal. Juvenile urchins, however, remain sensitive to acidification and show up to a nine-fold increase in mortality ${ }^{2}$.

The impacts of acidification on sensitive species cascade across ecosystems. Copepods, a major food source for fish, are resilient but would be affected if their phytoplankton food source declined. In mussels, more abundant food may counterbalance the increased energy costs of resisting the impacts of ocean acidification ${ }^{1}$.

Increasing atmospheric $\mathrm{CO}_{2}$ will also

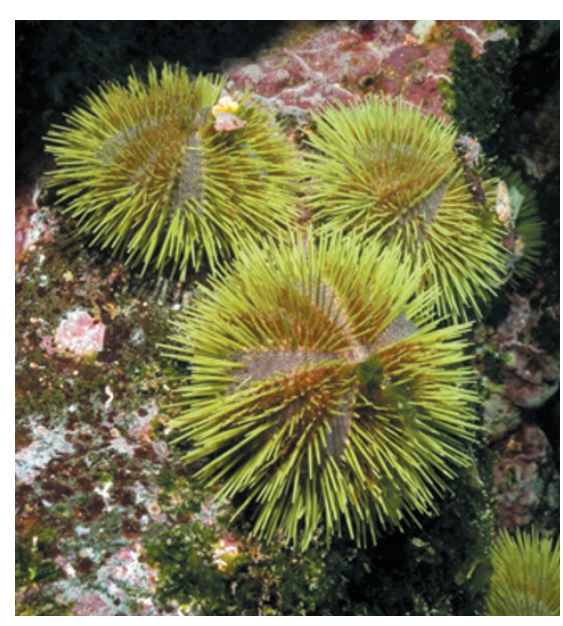

It takes up to 16 months for green sea urchins to acclimatize to acidified conditions.

cause average global temperatures to rise. Temperature is a key driver for biological change. Organisms specialize within certain temperature ranges and are sensitive to extremes. Ocean acidification modulates responses to temperature, and vice versa. Whereas mild warming on the cold side of a species' typical thermal range may be beneficial, exposure to higher temperatures enhances the sensitivity of some species, including Arctic spider crabs (Hyas araneus), to acidification ${ }^{3}$. The combined effects of local variability in acidity, temperature and human-made eutrophication or pollution may be more detrimental than for each factor alone.

To understand what future oceans might look like, marine scientists need to assess how whole ecosystems respond to rising acidity over time frames that are long enough to track generations of organisms to see which ones die or adapt. Because acidification develops in tandem with humandriven environmental changes, experiments must become more sophisticated and realistic. No single experiment can capture the complexity, so a variety of approaches will be needed.

Single-species investigations will remain valuable. Mesocosms - parts of ecosystems that are brought under controlled, experimental conditions - can unravel the role of some ecological interactions. Combined chemical and biological monitoring and modelling can reveal natural variability in ecosystem responses. Investigations of species within temperature and acidity gradients can help to assess which organisms will adapt.

\section{ECOSYSTEM EFFECTS}

Although researcher numbers, funding and methodologies will always be limiting, we think that the field is being held back by a much bigger problem - a lack of knowledge of the overarching principles for how ocean acidification affects species and ecosystems. These will be crucial for addressing issues including shifts in biogeochemical processes, such as nitrogen fixation, and the interactions between animals, plants and bacteria.

Elaborating these unifying principles will require an interdisciplinary approach that structures research within and between multinational and national projects on ocean acidification. The Ocean Acidification International Coordination Centre, announced in June 2012, is a welcome first step.

Ocean acidification is already affecting marine ecosystems and their services to humankind. In light of the millennia it will take to reverse changes in ocean chemistry, we believe that research should be oriented towards finding solutions, rather than to simply documenting the disaster. Ultimately, only the reduction of atmospheric $\mathrm{CO}_{2}$ levels will alleviate the challenges of ocean acidification. Meanwhile, researchers can improve understanding of the biological impacts of ocean acidification and identify the organisms and ecosystems that are most at risk. We can also buy some time through reducing human pressures such as overfishing, eutrophication and pollution.

Sam Dupont is a marine biologist at the University of Gothenburg, Kristineberg, Sweden. Hans Pörtner is professor of ecophysiology at the Alfred Wegener Institute, Bremerhaven, Germany.

e-mail:sam.dupont@bioenv.gu.se

1. Thomsen, J. et al. Biogeosciences 7, 3879-3891 (2010).

2. Dupont, S., Dorey, N., Stumpp, M., Melzner, F. \& Thorndyke, M. Mar. Biol. http://dx.doi. org/10.1007/s00227-012-1921-x (2012)

3. Pörtner, H. O. \& Farrell, A. P. Science 322, 690-692 (2008). 